Kauffman Foundation Research Series on City, Metro, and Regional Entrepreneurship

\title{
Examining the Connections within the Startup Ecosystem: \\ A CASE STUDY OF ST. LOUIS
}

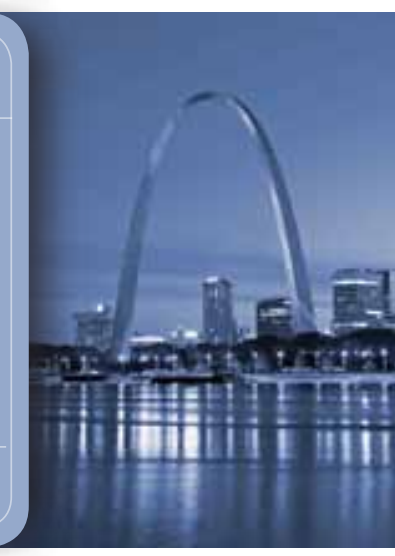

Yasuyuki Motoyama, Ph.D.

Ewing Marion Kauffman Foundation

Karren K. Watkins

Washington University in St. Louis

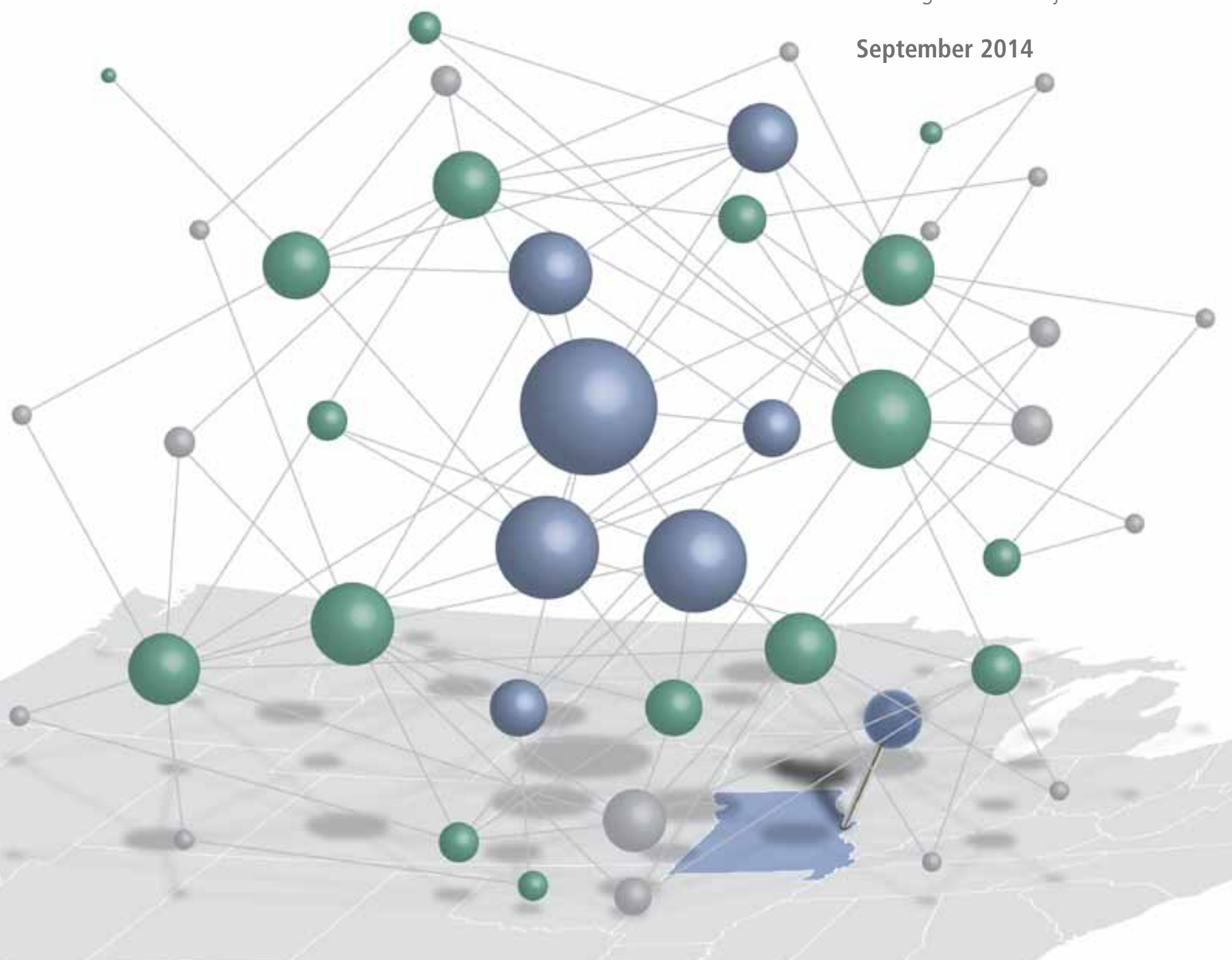




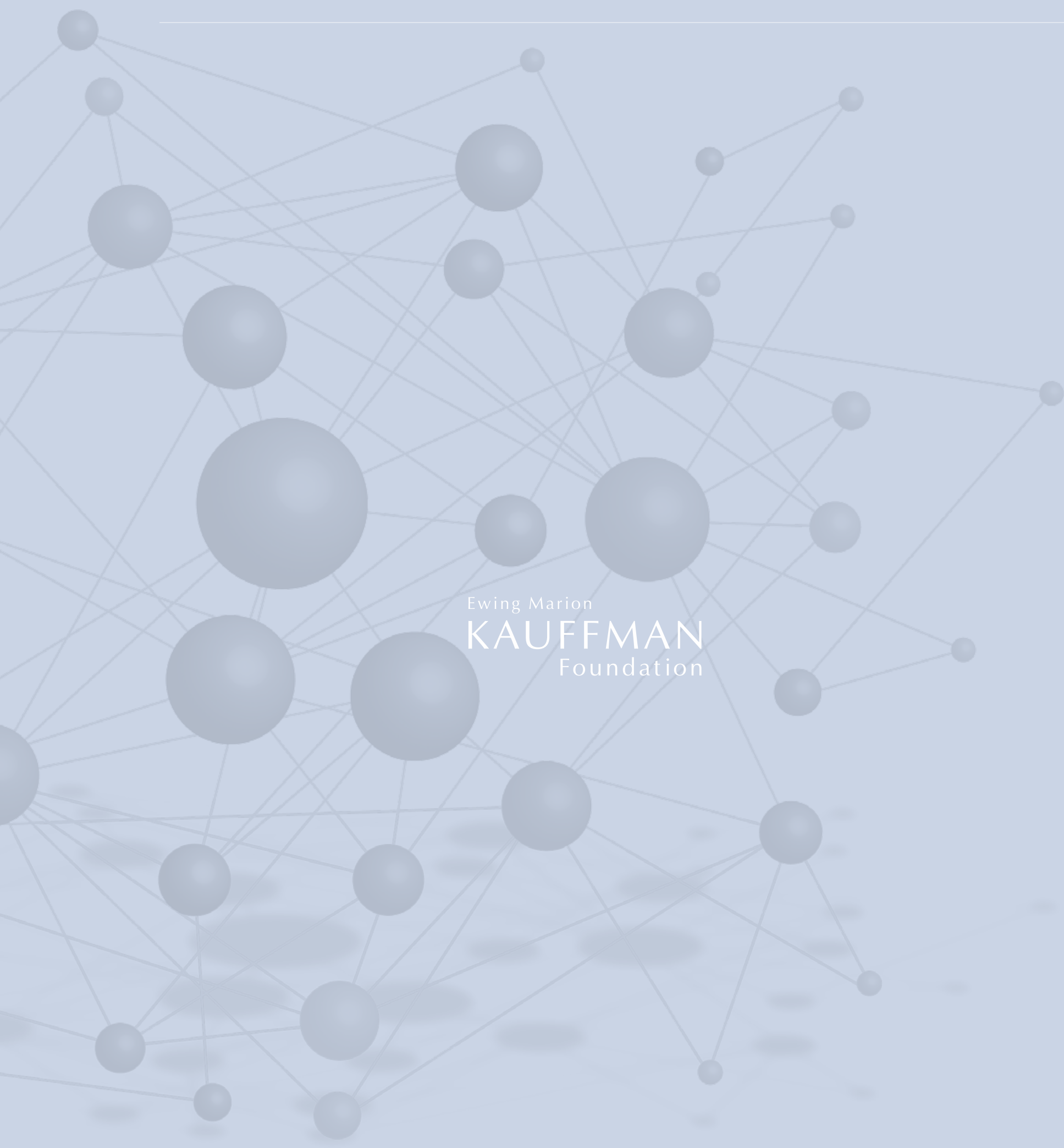




\section{Foreword}

$\mathbf{T}$

he recent growth of the startup scene and entrepreneurial community in St. Louis is incredibly exciting. It means economic progress for the St. Louis region and more jobs available for St. Louis citizens. Many newly formed local assets, such as ITEN, T-Rex, and Arch Grants, are laying a foundation that will have impact for decades to come.

In this paper, Yas Motoyama from the Ewing Marion Kauffman Foundation, and Karren Watkins from Washington University, document the resurgence of entrepreneurial activity in St. Louis by reporting on the collaboration and local learning within the startup community. This activity is happening both between entrepreneurs and between organizations that provide support, such as mentoring and funding, to entrepreneurs. As these connections deepen, the strength of the entrepreneurial ecosystem grows.

Another finding from the research is that activity-based events, where entrepreneurs have the chance to use and practice the skills needed to grow their businesses, are most useful. St. Louis provides a multitude of these activities, such as Startup Weekend, 1 Million Cups, Code Until Dawn, StartLouis, and GlobalHack. Some of these are St. Louis specific, but others have nationwide or global operations, providing important implications for other cities.

St. Louis is a unique city with its own history, people, and culture. Yet, it shares many social and economic features with other cities across the nation. Although this paper's focus is St. Louis, other cities can draw lessons from our experiences, and I hope this research sparks a dialogue about what entrepreneurship practices and policies they might consider and why.

There is still much to learn, of course, as our entrepreneurial community is in its early stages, and there will undoubtedly be bumps along the way as we evolve. Because of this research, however, we will be able to do that growing in an informed, thoughtful way.

Mayor Francis G. Slay

City of St. Louis 


\section{EXECUTIVE SUMMARY}

Recent research has shown that the job-creating potential of new, young and growing companies is vital to the U.S. economy. Other studies show that a community's entrepreneur support network - the organizations and institutions that make up its "ecosystem" -is critical for new firms to succeed. What we do not know much about, however, is how to establish such an effective local ecosystem.

Traditional methods used to evaluate entrepreneurial ecosystems have focused on sizing up risk capital, incubators, a supportive culture, or other elements in an entrepreneurial community. We believe there is significant room for improvement by focusing instead on the relationships between these elements and the evolution of an ecosystem over time.

As a region seeks to successfully cultivate entrepreneurship, a keen understanding of how, when, or why different players interact with one another and how the ecosystem evolves is likely to make both public- and private-sector behavior more effective. Similarly, to identify potential policy implications, it is far more useful to analyze how successful ecosystems have developed over time-particularly how each got its start-than to attempt to copy a developed ecosystem.

This research is based on a case study of the startup ecosystem (a segment of an entrepreneurial ecosystem) in the St. Louis area. St. Louis was chosen because it has not been known as an entrepreneurial hub and because the recent, substantial transformation of its local entrepreneurship ecosystem provides greater implications for the evolution of the ecosystem.

\section{Key Connections}

We investigated four key connections within the ecosystem: connections between entrepreneurs; connections between formal support organizations; connections entrepreneurs have to key support organizations; and connections entrepreneurs have to other forms of support, such as to other entrepreneurs in the area, periodic entrepreneurship-oriented events, or other relevant organizations. Elements traditionally associated with entrepreneurship, such as incubators or venture capital firms, emerged only lightly in our study.

\section{Level 1: Connections Between Entrepreneurs}

Connections between entrepreneurs were extremely valuable and weighty. The 2013 Arch Grants recipients created a community for learning and support, constantly observing each other's progress and providing feedback about each other's businesses. These interactions consistently extended beyond the industrial sector. Another critical aspect was the connections between novice and experienced entrepreneurs. Entrepreneurs learned the most from other entrepreneurs and from mentors who had entrepreneurial experience.

\section{Level 2: Connections Between Support Organizations}

Support organizations collaborated and coordinated to a high degree. Many connections between these organizations, such as shared board members, were strategic and functional, but there also were loose connections, including attending events organized by other organizations, serving on panels at those events, and jointly organizing events. Detailed back-stage discussions between the support organizations helped to avoid unintentional and unnecessary overlaps of support for specific companies. At the same time, the emergence of new support organizations, concerns over redundancies, and recent top leadership changes at support organizations all point to a constant reorganization of support organizations within a region, at least in this early stage of ecosystem development. This indicates that injecting "missing elements" of support is not sufficient to create a healthy ecosystem, but that the relationships between support elements matter the most.

\section{Level 3: Connections Between Entrepreneurs and Key Support Organizations}

We identified two types of support that organizations gave to startup companies: broad types, such as mentoring and connecting, and financial and functional types, such as business model assistance, pitch practice, and incubation. The most heterogeneous support was mentoring, which many support organizations identified as their primary service. 
In observing universities functioning as sources of entrepreneurs, it was students or post-doctoral researchers, not professors or technology transfer offices, that commercialized university-based technologies. Of those interviewed, this happened exclusively with pharmaceutical or biotech firms.

\section{Level 4: Miscellaneous Support Connections}

Multiple entrepreneurs said there were several events they attended and found valuable. Many of these were open events organized by other support organizations, such as BioSTL, Lab1500, and Center for Emerging Technologies. The co-location of many grant recipients allowed support organizations to use these types of events as catalytic activities to connect entrepreneurs who might not otherwise meet. Moreover, we identified four other events, attended by multiple entrepreneurs, that were not run by formal organizations, but by groups of grassroots volunteers: Startup Weekend, Start Louis, Build Guild, and Code Until Dawn.

\section{Implications}

Our research offers these lessons for those involved in local or regional startup ecosystems:

- $\quad$ Focus on connecting entrepreneurs to enhance learning between entrepreneurs. This can be done by injecting catalytic events.

- Communicate and collaborate with other entrepreneurial support organizations for constant readjustment of the local ecosystem.

- Cultivate a list of experienced local entrepreneurs to connect them to nascent entrepreneurs.

- Support organizations should recruit staff with entrepreneurial experience.

- If a public venture fund has already been established, distribute smaller prizes to multiple startups, instead of one large prize, so that a group of entrepreneurs can become a cohort.

- If incubators already exist, reorganize them to connect entrepreneurs and enhance peer- learning. Co-locate and integrate support organizations with incubators.

\section{Conclusion}

Cooperation between support organizations in the St. Louis area has undoubtedly played a key role in the evolution of this ecosystem by connecting entrepreneurs with the types of support they need, when they need it. One of the most critical support types was other entrepreneurs with specific expertise or experience.

We saw that Arch Grants played a large role in creating a community of entrepreneurs. It did this by dispersing multiple small grants, which established large cohorts of entrepreneurs, as many as twenty per group; carefully streaming its efforts to integrate with local entrepreneurship assets, such as encouraging its recipients to co-locate in specific locations, which further enhanced the interaction between them; and connecting them to local key support organizations, such as ITEN, BioGenerator, and others. As of July 2014, one year after the award, the twenty recipients have created 104 jobs, generated more than $\$ 2.8$ million in revenue, and raised more than $\$ 17$ million in investment (See Appendix 2).

Because our study is an exploratory and descriptive project, we cannot yet tell how well the companies will thrive and the startup ecosystem will evolve. However, we hope that this research informs other communities of how to build a strong entrepreneurial ecosystem and conduct research to gauge success. 


\section{INTRODUCTION}

We have known that entrepreneurship plays crucial roles in economic development. More than a century ago, Schumpeter (Schumpeter 1912) theoretically uncovered the role of entrepreneurs in the famous process of "creative destruction," or innovations. More recent empirical works have demonstrated that startup and young firms (five years old or younger) generate virtually all net jobs in the United States (Haltiwanger 2012; Haltiwanger, Jarmin, and Miranda 2013).

We also have known that entrepreneurship is largely a local phenomenon (Malecki 1994; Feldman 2003). It is well known that Silicon Valley possesses a unique structure and culture that distinguishingly produces corporate and university spin-offs and networks through which entrepreneurs themselves and venture capitalists interact (Saxenian 1994; Kenney 2000; Lecuyer 2006). Similarly, nationwide empirical investigation has revealed that rates of entrepreneurship vary substantially by metropolitan regions (Acs and Armington 2006).

Nonetheless, we have limited knowledge about the local system of entrepreneurship. While classic urban development theories (Marshall 1898; Castells 1989) and the cluster theory (Porter 1994, 1998) touched some on the notion of entrepreneurship, they treated entrepreneurship as one of the peripheral, externality factors with some high or low rates at certain locations, but provided no analysis about the structure, network, or composition of local systems of entrepreneurship. The same limitation applies to innovation studies, such as the regional innovation systems (Cooke 1998; Cooke and Morgan 1998; Lundvall 1992) and the Triple Helix model (Etzkowitz and Dzisah 2008; Etzkowitz and Leydesdorff 2000).
We were able to identify only a handful of studies directly discussing this subject of the entrepreneurship "ecosystem," and we consider this a critical omission. Moreover, the limited past studies on this subject tended to focus on identifying a broad list of elements in the ecosystem, but lacked any analysis on the connections between those elements. In our view, it is more important to analyze how and how well those elements are connected than what those elements are. In this article, we conduct a ground-level observation of specific actors and organizations in order to understand the connections more concretely. We provide a more parsimonious model of entrepreneurship ecosystem with rich context about the connections between the elements of the ecosystem, particularly between entrepreneurs and key support organizations.

\section{LITERATURE REVIEW}

The local system of entrepreneurship is an understudied subject, and we could identify only a handful of related studies, unlike plentiful studies of industrial clusters or systems of innovations. According to Van de Ven (Van de Ven 1993), the lack of research on this subject came from the exclusive focus by earlier academic studies of entrepreneurship on individual characteristics and behaviors of individual entrepreneurs. In other words, the past studies tended to ask who the entrepreneurs are and what kind of individual traits lead them to success.

In contrast, Van de Ven advanced the concept of the "social system framework" by identifying actors broadly engaged in innovations and entrepreneurship at the local scale, such as a university and its scientific research, financing and insurance arrangements, and the human competence pool.

\section{Successful ecosystems are, by definition, highly developed. It would be much more useful if we could answer how those successful ecosystems have developed over time and, particularly, how each ecosystem started.}


Subsequently, Neck and his colleagues (Neck et al. 2004; Cohen 2006) cultivated the framework with observation based on Boulder, Colorado, and identified six elements: incubators, spin-off firms, formal and informal networks, physical infrastructure, and culture. Similarly, Feldman (Feldman 2001) uncovered that pioneering entrepreneurs, supportive social capital, venture capital, entrepreneurial support services, and engaged research universities contributed to the successful establishment of an entrepreneurial culture in the Washington, D.C., area.

Reviewing these past works leads us to identify three major limitations. First, the past studies focused on identifying elements of a system and hardly analyzed the connections between them. We do not argue that the past works ignored the aspect of connections. Indeed, they often stressed the importance of 'networks' as one of the elements, but we think it was insufficient. There is a wide range in networks: formal networks with organized associations may fit better as an element in the framework, while informal networks-the state of two or more individuals being connected-are more difficult to conceptualize. Treating them as one generalized group will cause enormous ambiguity about how each element can be defined or acts, and how different elements interact. Comparably, social capital is an extremely broad concept. It can mean the presence of specific actors or the state of having high-level interactions between them. Culture is an even broader concept. One can provide a highly generalized definition and a few examples, but it does not help to disentangle the system, its elements, and its interactions.

Such examination of interconnectedness is enormously challenging, and the blame should not fall onto these past studies on entrepreneurship ecosystem alone. Many regional development theories, which study both actors (individuals and firms) and aggregated units (communities and industries), have long struggled to conceptualize and examine those externality aspects.

The second major limitation of the past works is their tendency toward a holistic framework, which often ended up with an inclusive approach to any possible elements. It is easy to imagine that, under the social system framework, there can be many elements involved, if only tangentially. We already listed the common ones: venture capital, specialized entrepreneurship support organizations, research universities, incubators, and a pool of skilled labor. What is missing is a critical examination of which elements are essential actors. Such insight can provide more concrete implications for how to establish or promote the local ecosystem from a policy perspective.

Popular media followed more or less on the inclusive and element-focused approach. For instance, the Financial Times (Moules 2014) reported that Kansas City, Missouri, could reach its full potential by enhancing connections with large corporations and universities, attracting venture capital money, establishing an international airport, and celebrating local heroes. Similarly, Forbes (Cohn 2013) argued that the assets of the St. Louis, Missouri, ecosystem came from local universities, local venture capital firms, wealthy angels, support organizations, and the pool of talent. In general, the media's approach is either to pose naïve optimism by listing the general elements a region possesses, or to call for a policy action by pointing out the missing element(s). Lack of finance and talent are the most hotly debated topics.

In contrast, a few selective practitioner-based studies have challenged the necessity of certain elements that conventionally were believed to be elements of the ecosystem. Feld, a successful entrepreneur, mentor, and investor, openly asserted that the university research function did not contribute to the vibrant startup community in Boulder, Colorado (Feld 2012), a region identified as having a high level of startups by many measures, including the Business Dynamics Statistics of Census (Konczal 2013) and the list of high-growth Inc. firms (Motoyama and Danley 2012). Instead, University of ColoradoBoulder indirectly helped the community by opening up its lecture halls for large local entrepreneur and supporter meetings. Chapman (Chapman 2011) not only agreed about the research university role, but also found that the sheer volume of investment means little about the vibrancy of the startup community, but 
that the connectivity between investors and investees, transparency, liquidity, and governance of finance are the keys for regional success.

Those practitioner-based studies provided further insights. Most notably, Feld (Feld 2012) presented four postulates of a vibrant startup community: 1) Entrepreneurs, not professors, policymakers, or agency administrators, must lead the entrepreneurial community. 2) The community must have a porous boundary by including the entire stack of entrepreneurs, from experienced serial entrepreneurs to nascent entrepreneurs. 3) The community must have organized activities that engage people in the entrepreneurial context. No cocktail parties and networking receptions. 4) Community leaders must commit for the long term, at least twenty years. Hwang and Horowitt (Hwang and Horowitt 2012) similarly stressed the importance of openness in the Silicon Valley ecosystem and additionally argued that recipe matters more than ingredients. While Isenberg (Isenberg 2013) explicitly listed the six elements, he also emphasized the importance of 'high-order interactions' and self-sustainability of the ecosystem. These findings contribute to describing the general characteristics of the ecosystem that past academic studies have little investigated. Moreover, their challenges of the need for certain elements of a system indicate a gap between academic and practitioner findings and the need for more critical examination.

The third and related limitation of past studies is their lack of power to analyze the evolution of ecosystems. It is natural to study the ecosystem of visibly successful regions, such as Silicon Valley (Saxenian 1994; Lecuyer 2006) and Boulder (Feld 2012). However, those successful ecosystems are, by definition, highly developed. For policy implications, it would be much more useful if we could answer how those successful ecosystems have developed over time and, particularly, how each ecosystem started. This presents enormous challenges for scholars, as we have to trace the history of a region for easily a few decades. Feld (Feld 2012) admitted that much of the foundation of Boulder's startup community was built more than twenty years ago, before he arrived there.
In this evolutionary perspective, Feldman (Feldman 2001) was the pioneer to analyze how Washington, D.C.'s ecosystem has emerged since the 1980s. However, she induced four elements from the past literature-finance, supportive social capital, support services, and research university (p. 863) —not based on a critical analysis of whether each element was crucial for Washington's ecosystem. Moreover, she analyzed the evolution of each element separately and did not investigate the connections between them.

Intentionally or unintentionally, the three limitations of the entrepreneurship ecosystem literature we raised here apply equally to the cluster theory, a study that holistically summarized industrial agglomerations. Indeed, both the ecosystem and cluster theories identified essentially the same elements. Porter (Porter 1994, 2000) listed risk capital (such as venture capitals), specialized support services, research universities and corporate research labs, core customers, and a labor force. His stylized diagram of the wine industry in California (Porter 1998) showed some loose configuration of related subsectors, but fell short of explaining how, exactly, and how much, those actors are connected. Despite Porter's insistence on the importance of interconnectedness and dynamic evolution, the cluster theory has not yet provided sufficient explanation of either (Motoyama 2008). So far, the entrepreneurship ecosystem literature has followed the same trajectory.

\section{SITUATING THE CASE OF ST. LOUIS}

In the previous section, we identified the three major limitations of the past academic studies about the entrepreneurship ecosystem: the focus on elements without much attention on connections between them, the holistic and inclusive approach that came up with essentially the same list of elements as the general industrial cluster theory, and the lack of evolutionary analysis.

In this article, we propose a different approach to overcome those three limitations. First, we focus 


\section{The question should be about what the system's most critical elements are, how (and how well) they are or are not connected, and how they evolve.}

on describing the connections between elements of a system. While geographic studies have an advantage in holistically capturing phenomenon in a given region, their primary observation on aggregated units, such as industries, a labor pool, and some undefined collection of firms in the similar industrial activity, as well as their competition and collaboration, is not suited to analyze the connection between elements. A connection, by definition, is an action between specific actors. Thus, we need to focus on analyzing specific actors, individuals and specific organizations, instead of aggregated ones.

Second, we find that discussing which element can be included in the ecosystem is little productive. Once you start this debate, it is likely to end up with a broadly inclusive list, because researchers do not want to be criticized for missing any element that may be included. Furthermore, it gives the impression that the broader inclusion provides a more comprehensive theory and system. Thus, the question should be about what the system's most critical elements are, how (and how well) they are or are not connected, and how they evolve.

Third, the holistic approach implies the homogeneity of ecosystems. In other words, the past studies assumed that, whatever the different local, industrial, and entrepreneurial structures are, the entrepreneurship ecosystems in different regions should look alike in the theory. In contrast, we start with an assumption of heterogeneity. Different regions can have different ecosystem structures. Thus, in this paper, we take a minimalist approach and start with the two most essential elements of the entrepreneurship ecosystem: entrepreneurs and entrepreneurship support organizations. Here, we emphasize support organizations that directly focus on entrepreneurship, and do not necessarily include general economic development agencies. We analyze the interactions between entrepreneurs themselves and between entrepreneurs and support organizations. Subsequently, we analyze what other actors and organizations are involved in the process of entrepreneurship. In sum, we use a highly exploratory and descriptive approach by minimizing the normative debate of what the system should look like.

Fourth, we focus on the startup ecosystem, a segment of the entrepreneurship ecosystem. Due to the understudied nature of the subject, we should not assume the existence of a holistic entrepreneurship ecosystem. Here, we find that investigating entrepreneurship is challenging because there are different types of entrepreneurship, from mom-and-pop shops and lifestyle consultants to highly scalable companies with or without technologyintensive products. Additionally, the ecosystem of startup entrepreneurship, i.e., very early-stage entrepreneurship, may be contextually different from the ecosystem of high-growth entrepreneurship, in which existing companies with a certain scale of revenue are trying to expand rapidly. We will explain our focus on the startup ecosystem in detail shortly.

Fifth, we investigate a region that has not been known as a hub of entrepreneurship, but has been undergoing a substantial transformation within its local entrepreneurship ecosystem: St. Louis, Missouri. Our ground-level observation has indicated that the landscape of entrepreneurship has changed substantially in the past few years (Duttia, interview, August 24, 2012; Harrington, interview, December 10, 2012), and the similar observation was reported by a detailed journalistic report (Reilly 2014). The macrolevel data of Business Dynamics Statistics additionally demonstrates a sharp recovery of startup creation in 2010 and 2011, much higher than the national rate. While we cannot prove that this changing landscape of entrepreneurship in St. Louis will sustain and fully develop, we believe there is a good amount of 
evidence to indicate the evolution of this region's ecosystem.

\section{About the St. Louis Region}

We begin by providing brief information about the region. Throughout the last half century, St. Louis largely has been known as a "big business" city, home to many stable national and global corporations. Anheuser-Busch, Nestlé Purina Petcare, Emerson Electric, Enterprise Rent-A-Car, and A.G. Edwards are just a few of these. The 1990s, however, saw the cumulative effects of many years of economic decline. For instance, Southwestern Bell Communications (now AT\&T) relocated its headquarters from St. Louis to San Antonio, Texas, in 1993 (St. James Press, 2000); the Great Flood of 1993 devastated the region (Larson, 1996); McDonnell Douglas was purchased by Boeing in 1996 (Knowlton 1996); and, later, Anheuser-Busch was purchased by the Belgian-Brazilian company InBev in 2008 (De la Merced 2008). The restructurings by so-called 'anchor firms' led the region to undergo significant economic changes, particularly reflected in a reduction in manufacturing jobs, downsizing and acquisition of major corporations, decline and then gentrification of the urban metro area. Combined with the nationwide economic downturn of 2008 , the late 2000s saw St. Louis as a city with a surplus of skilled, unemployed workers and a need for new engines of economic development.

Both the public and private sectors invested enormous effort in reinventing the region, including the state economic development agency, the Greater St. Louis Chamber of Commerce, local universities, and prominent community figures such as John McDonnell and Bill Danforth. Two prominent reinvention strategies emerged by 2010: the Mosaic Project to attract immigrants to the area, and the promotion of entrepreneurship. In addition, Washington University in St. Louis's Skandalaris Center for Entrepreneurship, founded in 2003 through a Ewing Marion Kauffman Foundation grant, became progressively more involved with the community, and many new entrepreneurship support organizations have launched since 2011 (see Table 1).

One such support was the creation of Arch Grants, a nonprofit corporation founded in 2011 by Joe Schlafly, a venture capitalist and proponent of St. Louis economic development, and Jerry Schlichter, a lawyer invested in the region's success. Arch Grants' goals are to make St. Louis an attractive place for startup businesses to launch and to increase employment growth in the city. To achieve these goals, Arch Grants holds an annual business plan competition that awards a package of prizes to each of twenty winners. Arch Grants seeks companies that are early-stage, scalable, and have disruptive, unique ideas, and each recipient receives $\$ 50,000$ in equity-free cash. In return, companies who accept the Arch Grants award must agree to locate their business in St. Louis for the following year. ${ }^{1}$ Startups from any sector may apply.

It is worth noting that public-sector interventions have not been effectively conceived in past evaluation studies, particularly studies about incubators (Amezcua 2010) and public venture funds (Lerner 2009). We do not assume that a company receiving Arch Grants funding necessarily denotes an entrepreneurial success. It only confirms that a firm was able to launch its business with a modest amount of cash awarded by a semi-public entity. However, tracing the Arch Grants recipients provides us a framework to capture a group of startup firms in the region, and it is suitable for our focus on the startup ecosystem. Furthermore, all these collective efforts by the public, semi-public, and private sectors demonstrate a case that can produce direct policy implications.

1. Arch Grants does allow a few recipients to locate outside of the downtown St. Louis area. A startup may be granted this exclusion if the "nature of their business precludes them from" locating downtown, in which case the business must receive permission to locate elsewhere in the St. Louis region (Arch Grants 2014a). 
Table 1. Entrepreneurship Support Organizations in St. Louis

\begin{tabular}{|c|c|c|}
\hline Organization & Target Industry & Founded \\
\hline Center for Entrepreneurship (St. Louis Univ.) & All & 1987 \\
\hline Skandalaris Center for Entrepreneurial Studies (Washington Univ. in St. Louis) & All & 2001 \\
\hline CORTEX & Life sciences & 2002 \\
\hline BioGenerator & Life sciences & 2003 \\
\hline INNOVATE/NMS ${ }^{2}$ & All & 2007 \\
\hline IT Enterprises (Univ. of Missouri, St. Louis) & Life sciences, IT & 2008 \\
\hline ITEN & IT & 2008 \\
\hline BioSTL & Life sciences & 2011 \\
\hline T-REX & IT & 2011 \\
\hline Capital Innovators & All & 2011 \\
\hline Helix Center & Biotech & 2012 \\
\hline Lab1500 & All & 2012 \\
\hline STLVentureWorks & All & 2012 \\
\hline Arch Grants & All & 2012 \\
\hline 1 Million Cups & All & 2013 \\
\hline
\end{tabular}

The twenty 2013 Arch Grants recipients were from various sectors, with products and services ranging from women's triathlon apparel to mobile advertising solutions. For purposes of this report, we anonymized startups according their sector. We classified eight companies as "Biotech," another eight companies as "IT/Information Services," and the remaining four as "Other" —which are either manufacturing- or education-focused.

We started to interview these Arch Grants recipients in late 2013 and were able to reach sixteen out of twenty. Incidentally, the four companies we could not interview or that declined to be interviewed were located outside the St. Louis region. Then, we expanded our interviews to key support organizations mentioned by the sixteen startup companies.

\section{ANALYSIS}

Our core analysis is to observe the connections between entrepreneurs and other key players in the region. This analysis led us to identify the connections within the ecosystem at four levels.

2. Currently Gateway VMS. 


\section{Level 1: Connections Between Entrepreneurs}

The first level is the connections between entrepreneurs. About two-thirds of Arch Grants recipients have reported periodic interactions with other Arch Grants recipients, and Figure 1 visualizes the relationships.
This does not necessarily mean that all of the companies developed dense relationships with each other. Of the sixteen recipient companies we interviewed, twelve mentioned active relationships, while the four others did not mention any specific ties to other entrepreneurs. A few of the twelve companies were more active and expressed four or

\section{Figure 1. Connections between Arch Grants recipients ${ }^{3}$}

Eateria

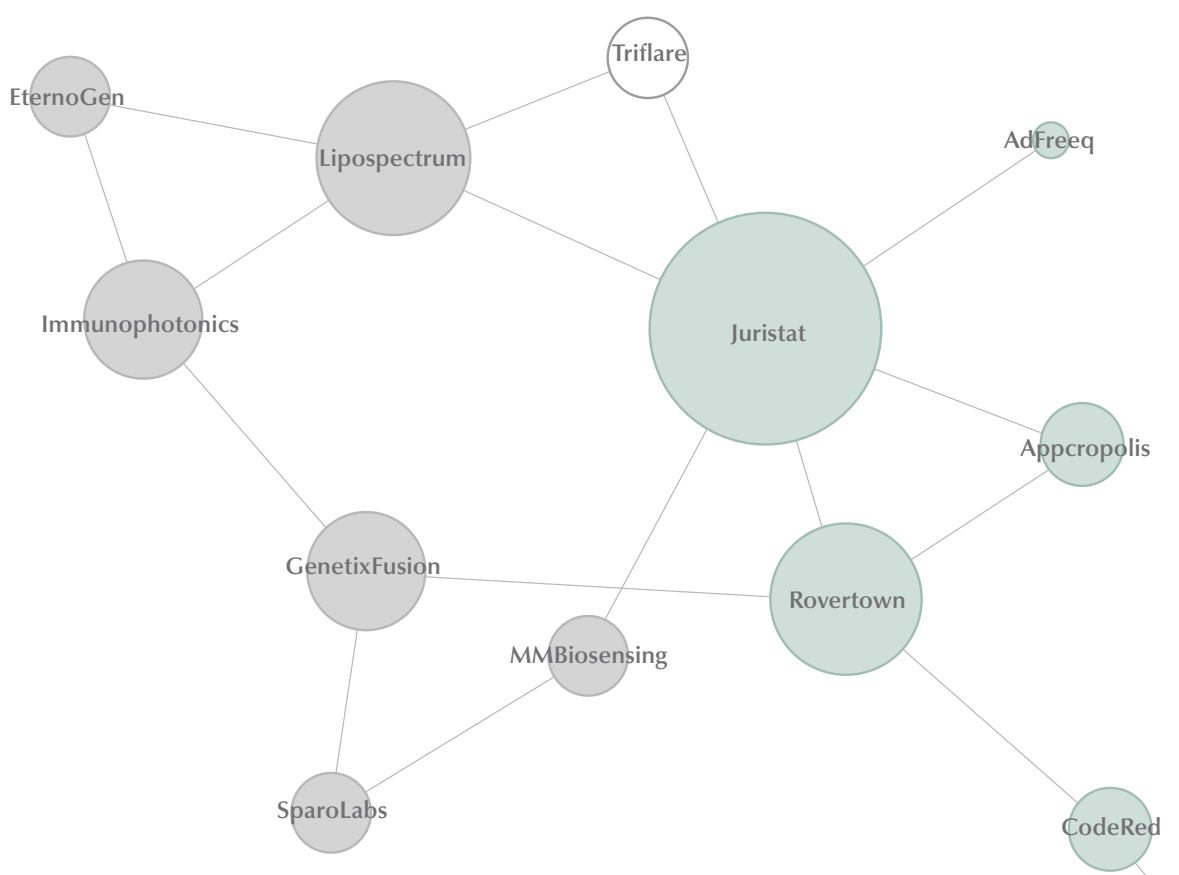

us Crilling

Adarza $\quad$ TrakBill 


\section{These interactions created an environment in which they not only could learn from their peers, but also support each other emotionally through the rough and uncertain journey they, as entrepreneurs, were facing.}

more connections to other companies, while most other companies expressed at least two connections. As coloring shows different sectors, the figure also demonstrates that biotech firms (shown in gray) had connections with other biotech firms, and IT firms (shown in light green) had connections with other IT firms.

These relationships suggest that Arch Grants' method of distributing the award to twenty companies created a recipient community in which those recipients constantly observed the progress of the other recipient companies and provided each other feedback about their businesses. Such a sense of community was expressed in multiple interviews through comments such as: "He [a founder of another Arch Grants recipient company] is a nice guy and he's really intelligent. He gives me a lot of advice, but I know I also bother him. But all of us grant recipients are friends, and it's like a fraternity or sorority" (Other Firm A). "It's a great environment. I had some questions about some of the frameworks that they [another recipient company] are using, and sometimes other people stop by and ask me things: what do you think about this idea?" (IT Firm A). The same entrepreneur provided a further example: "This guy came [by] yesterday and he almost pulled my ears. He said, 'You're going to need more customers. You have enough traffic and people that are engaged with you. Now you should put time on selling this.' I said, 'OK, let's have a second conversation and see what you're doing on your side because you need more traffic."

One biotech firm characterized the interaction with another biotech firm as follows: "What we wanted to do as the Arch Grants recipients and being in [the] life science space is that we wanted to get together and start working on these [government] grants [such as SBIR and STTR] ourselves. So, I'll get feedback from them on my grant and give feedback to them" (Biotech Firm A). The varied industrial sectors represented among the Arch Grants recipients did not seem to matter, and the interaction extended beyond those sectors. "You're doing completely different things. You're all building something and that involves kind of the same thought process, I like to think. Different expertise, but definitely the same thought process" (Biotech Firm B). These interactions created an environment in which they not only could learn from their peers, but also support each other emotionally through the rough and uncertain journey they, as entrepreneurs, were facing.

These interactions the entrepreneurs described quickly led us to the second and third levels of interactions by including key entrepreneurship support organizations in the region.

\section{Level 2: Connections Between Support Organizations}

The second level of connections is between the support organizations. Here, the connections we identified were not "some informal relationships," but strategic and functional ones. For instance, three support organizations had a monthly brownbag lunch to exchange information: ITEN, a support organization for information technology startups; BioGenerator, the similar one for biotech and pharmaceutical startups; and STL VentureWorks, a support organization that provides incubation space. This coordinated relationship was reflected in crossover relationships with their board 
members, such as those among STL VentureWorks, Cultivation Capital, and ITEN. Furthermore, the executive director of InnovateVMS, a mentoring service provider, previously worked at the Skandalaris Center at Washington University in St. Louis under a major grant initiative from the Kauffman Foundation. Thus, these two organizations naturally collaborated and shared networks of mentors. Moreover, two founders of Capital Innovators, an accelerator program, served as mentors of companies supported by ITEN. Other loose connections included attending events organized by other organizations, serving on a panel at those events, and jointly organizing events. These relationships are visualized in Figure 2.

\section{Level 3: Connections Between Entrepreneurs and Key Support Organizations}

The third level of interaction is the connections between the Arch Grants recipient companies and support organizations. Figure 3 gives a fuller picture of dense relationships between these actors.

Figure 2. Connections between support organizations

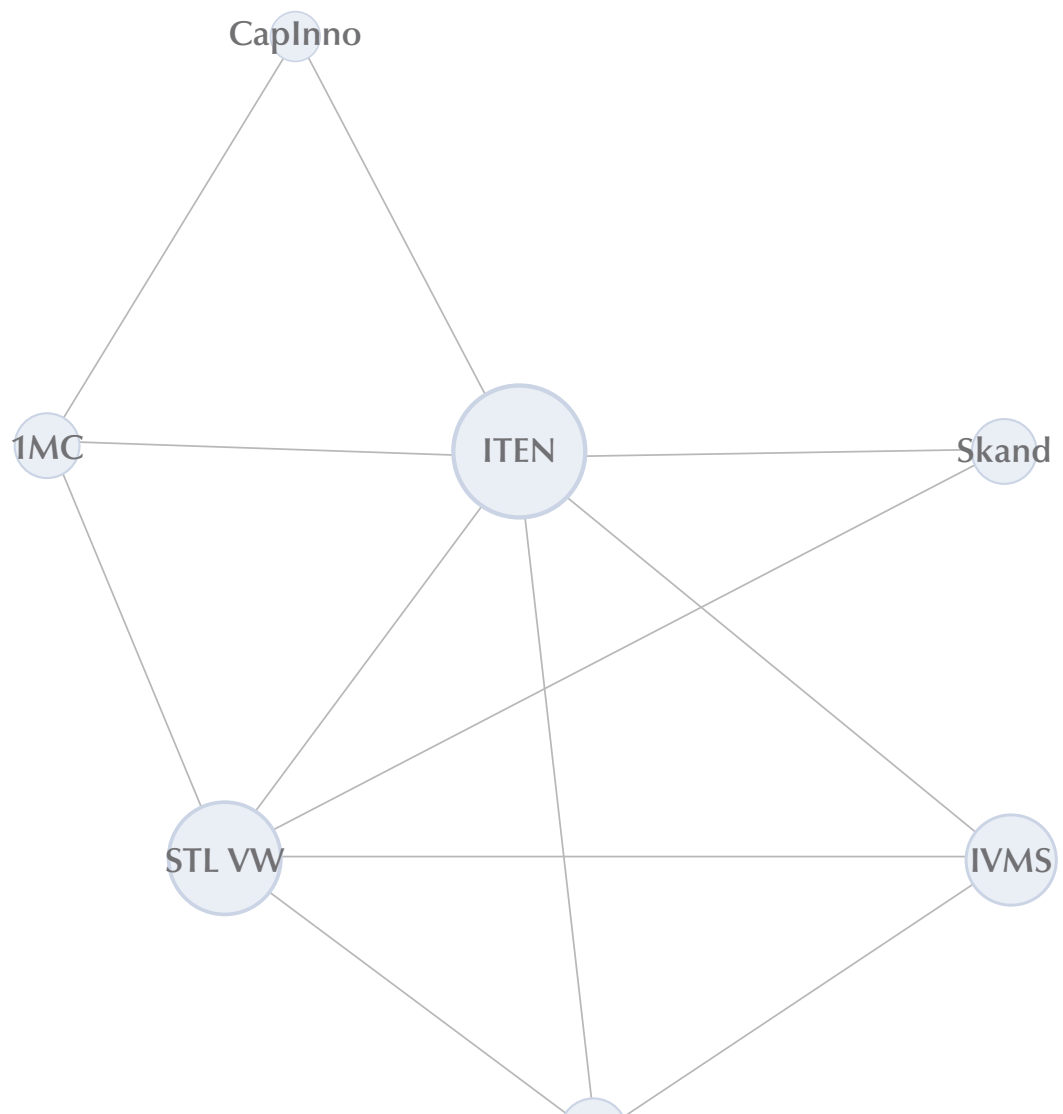

BioGen 
Figure 3. Connections between Arch Grants recipients and support organizations

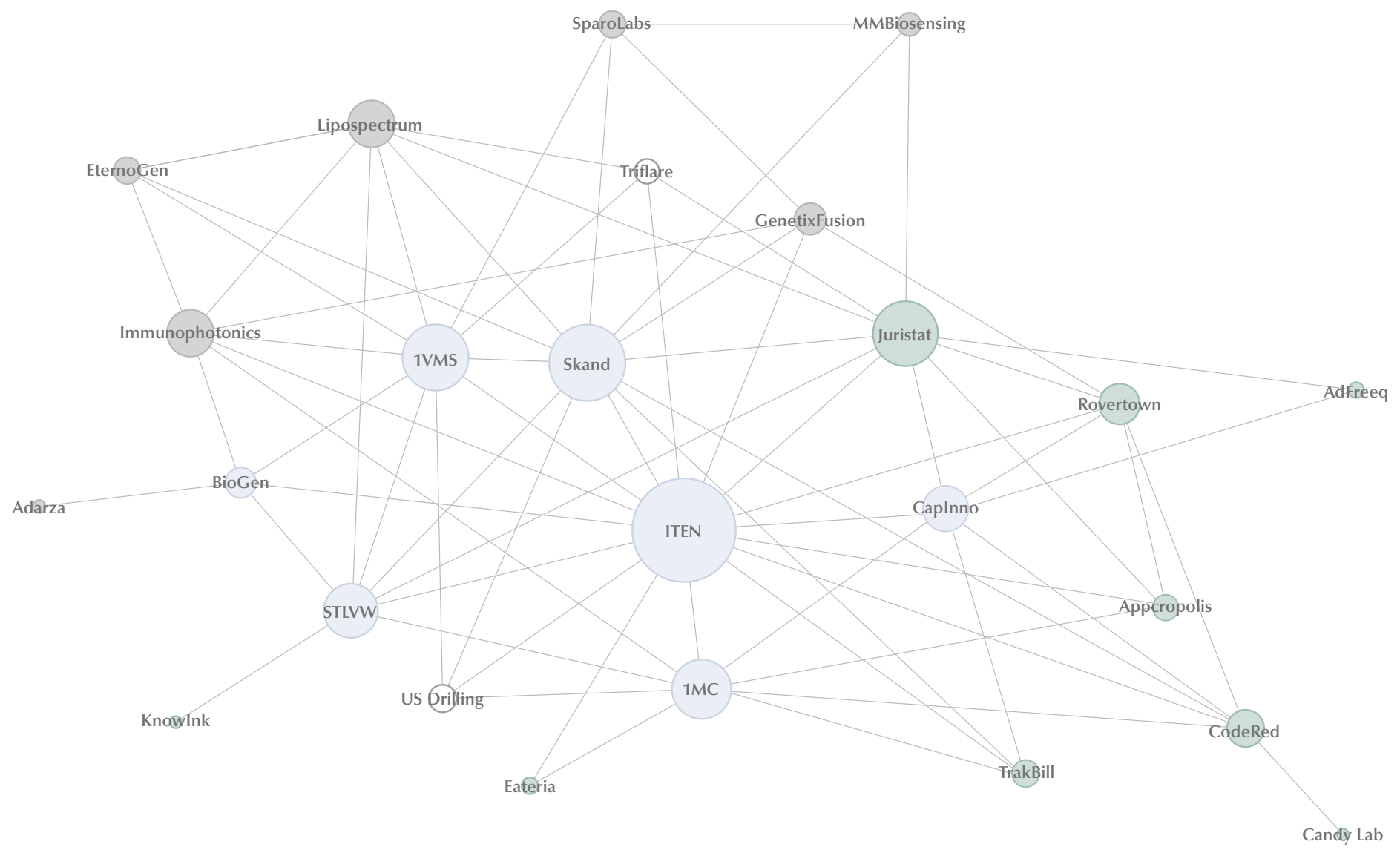

While Figure 1 (representing only company connections) showed five companies that were not connected to other companies, Figure 3 demonstrates that all five were not isolated, but had connections through at least one, and sometimes more, support organizations.

Perhaps more importantly, detailed information from the interviews can identify multiple layers of support provided by different supporting organizations. IT Firm C described its development process and the support it received as follows:
"We were then based in Chicago. [Another entrepreneur in St. Louis] set a date and introduced us not only to Capital Innovators [an accelerator], but also Arch Grants and even to Cultivation Capital [a venture capital firm]. [...]

"At the demo day of the Capital Innovators, [an angel investor] approached us and said he's interested in investing. That helps us bridge between Capital Innovators and Arch Grants, because we didn't get the money 
from Arch Grants until July 1. It also gave us a bargaining chip with Cultivation Capital. [...]

"Probably our biggest mentor to date has been Brian Matthews, who was our lead advisor and mentor for Capital Innovator, and he's also a principal at Cultivation Capital. [...]

"We hired two students from [Washington University in St. Louis]. The Skandalaris Center has already done matching students with companies with résumés ready."

These remarks show that financial support from Arch Grants, an accelerator, and a venture capital did not occur in isolation, but rather that the connections between different organizations led to financing of the company in stages.

Other Firm B expressed that the company's genesis was at the Missouri Venture Forum, a monthly meeting attended by 100 investors, entrepreneurs, service providers, and job seekers. One founder presented an idea during the two-minute forum, the other founder liked the idea, and they wrote the business plan together. The two periodically attended meetings organized by ITEN, 1 Million Cups (1MC), and the Skandalaris Center, and one served as a judge for the Skandalaris business plan competition. Lastly, this firm also received mentoring services from Innovate VMS.

Other Firm C mentioned that "the Arch Grants got us to ITEN, which got us to a business journal, which put us in touch with some of our client contacts. ITEN is a validity thing. They got us into the Startup Connection at the Science Center, where we won people's choice [. . . ] Then, ITEN put us in touch with Capital Innovators, which gives us practice in just pitching and selling, which is really valuable practice."

Thus, the connections between support organizations were not simple interpersonal connections in which directors of different organizations knew each other. Rather, the fact that the company received support or completed a program through a support organization functioned as an accomplishment and a validation. Interviews with those support organizations further revealed that the organizations' directors exchanged highly detailed information about specific companies, such as the company's stage, strengths and weaknesses, and what it has done in the past, including what did and didn't work (Interview, Brasunas, August 1, 2013; interview, Chmelir, August 1, 2013). These periodic conversations between support organizations helped to avoid unintentional and unnecessary overlaps of support. At the same time, some support and training took place continuously through different support organizations; for instance, reformulation of business model and expansion of customer base were not one-time processes, but required continual training that evolved over time.

\section{Level 4: Miscellaneous Support Connections}

The last and fourth level of connections we observed was those that went beyond entrepreneurs and support organizations to include other miscellaneous actors. These connections include other entrepreneurs in the area, periodic entrepreneurshiporiented events, and other miscellaneous organizations. To begin with, the connections between entrepreneurs extended beyond the cohort of Arch Grants recipients. The Arch Grants awarded fifteen companies in 2012, in addition to twenty in 2013, and several of the 2012 cohort interacted heavily with members of the 2013 cohort. For instance, IT Firm B expressed that it frequently interacted with the three IT firm recipients from the 2012 cohort. Manufacturing Firm A mentioned that founders of two companies from the 2012 cohort served as mentors. Additionally, one founder in the 2012 cohort served as a mentor for two companies in the 2013 cohort. Therefore, the peer learning effect was not strictly within each cohort. With entrepreneurship, one year could make a difference in terms of the learning curve and business development. Senior and experienced entrepreneurs were not the only formal mentors, but rather, the mixture of senior and peer interactions evolved into informal mentorships.

To keep relative simplicity in the network map, Figure 4 depicts the fourth-level connections mentioned 
by at least two firms in the 2013 cohort of Arch Grants recipients. To distinguish from earlier figures, the newly identified actors are represented in orange.

Interviews further revealed mentorship relationships with four local mentors with previous entrepreneurial experience who actively served as mentors for six Arch Grants recipient companies. We could not identify any specific patterns of how the entrepreneurs found those mentors: it could be by attending one of entrepreneurial events to be discussed below, by an introduction by support organizations, or by a referral from completely different acquaintances. However, the presence of four local mentors commonly serving multiple Arch Grants recipients indicates that, while the ways startup and experienced entrepreneurs met may seem random, the experienced mentors had specific network "circles." Once startup entrepreneurs got into the circles, they were able to build relationships with mentors relatively quickly-within a matter of months. These mentors were experienced entrepreneurs who were highly active and supportive of startups, and all interviewees mentioned that they

\section{Figure 4. Extended connections between Arch Grants recipients, support organizations, and other supporters}

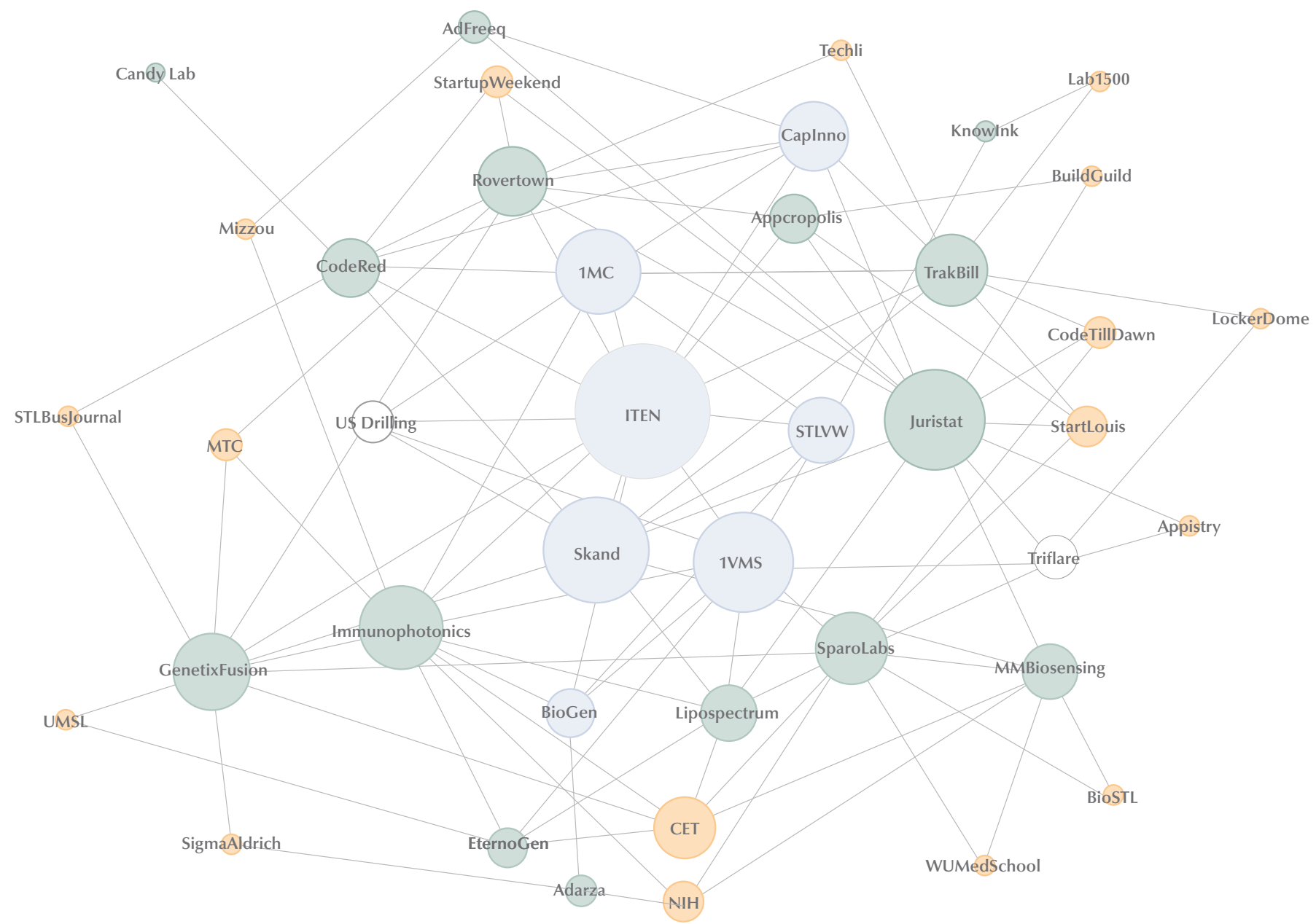


were generous, voluntary mentors willing to give back to the next generation of entrepreneurs.

In addition to the mentor relationships, multiple entrepreneurs mentioned seven entrepreneurial events as valuable. These were open events organized by other entrepreneurship support organizations, such as BioSTL, Lab 1500, and the Center for Emerging Technologies. Moreover, we identified four other important events that were not run by these kinds of formal organizations, but by groups of grassroots volunteers: Startup Weekend, Start Louis, Build Guild, and Code Until Dawn. ${ }^{4}$ Table 2 provides a brief explanation of each event.

Five out of six biotech firms mentioned connections with local or regional universities: University of Missouri at Columbia (Mizzou), University of Missouri at St. Louis, and the Washington University School of Medicine. The common pattern we observe is that the founders were graduate students or postdoctoral researchers at each campus who then started companies based on technologies and expertise in which they were trained. In other words, entrepreneurs did not reach universities to seek technologies for commercialization, nor did entrepreneurs and professors work together on technology commercialization. The role of professors, rather, was restricted either to introducing other academic researchers in the related technological or scientific fields, who were not necessarily based in St. Louis, or to serving on companies' advisory boards. Note that serving on a company's advisory board was completely different from involvement in operating a company or service as a business mentor, as mentioned previously, but usually limited to advice on specific scientific and technological matters.

Two other miscellaneous institutions are worth mentioning. While we did not identify involvement by traditional economic development agencies, Missouri Technology Corporation (MTC) was one exception. MTC is a semi-public state organization that aims to promote new and high-tech companies (MTC 2013). Three companies indicated using MTC's Venture Capital Co-Investment Program, so, in that sense, MTC's involvement was indirect. Investment decisions were made by local accelerators or venture capitals, and they additionally pulled resources from MTC.

Lastly, two interviewees mentioned the St. Louis Business Journal. In both cases, the local media also provided validation, as being mentioned in an article or

\section{Table 2. St. Louis Events Attended by Multiple Entrepreneurs}

\begin{tabular}{|r|l|}
\hline Event Name & Description \\
\hline Startup Weekend & $\begin{array}{l}\text { A weekend activity in which instant teams work on business plans and present by } \\
\text { Sunday afternoon }\end{array}$ \\
\hline Start Louis & $\begin{array}{l}\text { A monthly meetup of solo entrepreneurs and startup enthusiasts for learning and } \\
\text { collaboration }\end{array}$ \\
\hline Build Guild & A monthly meetup of web professionals \\
\hline Code Until Dawn & A monthly all-night coding event \\
\hline
\end{tabular}

4. These events are not represented as large dots in Figure 4, but do not undermine the importance of those events in the ecosystem. Our point here is that a collection of these events has substantially increased the connections, in addition to what the support organizations and other groups have provided. 


\section{The startup ecosystem and its structure, based on our ground-level observation, appeared to be substantially different from what was identified by past academic studies.}

receiving an award like "30 under 30" opened doors to new customers or other valuable business connections.

\section{DISCUSSION}

The startup ecosystem and its structure, based on our ground-level observation, appeared to be substantially different from what was identified by past academic studies. Virtually no studies empirically investigated the connections between entrepreneurs, which was one of, or perhaps the most, important aspects of our observation, at least as perceived by entrepreneurs. At best, the past studies could talk about the critical mass of entrepreneurs, but that literally referred to the sheer quantitative size. What matters more for entrepreneurs is the density within the mass of entrepreneurs. While Feldman (Feldman 2001) came closest to pointing out the presence of pioneering entrepreneurs, our research goes deeper on this aspect. First, it was not just the presence of pioneering entrepreneurs, but the mixture of nascent and experienced (pioneering) entrepreneurs that had significance. Second, the interaction between those two groups of entrepreneurs was even more important. Entrepreneurs learn from other entrepreneurs, and from mentors who have entrepreneurial experience. The interaction we observed repeatedly reflected the learning taking place between individuals.

Furthermore, this learning process was not exactly knowledge acquired through educational training from universities, but practical knowledge acquired through personal interactions and experimentally applied to a tailored case that each entrepreneur was facing at the moment. In that sense, the peers could provide feedback because they were facing similar problems, and the experienced mentors also could provide feedback because they had encountered similar problems before.

To infer from our observation, the common elements of the startup ecosystem were rather parsimonious: entrepreneurs, support organizations focusing on entrepreneurship, entrepreneurial events, and universities.

As mentioned before, this research is highly exploratory and, hence, inductive. We therefore have no intention of defining the entrepreneurship ecosystem deductively. Instead, what we induce from our observation is that the startup ecosystem required some critical mass of entrepreneurs, and that the interconnections between them helped them learn from each other and to innovate within their businesses. Several key support organizations, including Arch Grants, entrepreneurship-oriented events, and the flows of people between local research universities and startups helped to catalyze those interconnections between people and organizations.

Many past economic geography studies have used broad terms, such as culture (Neck et al. 2004; Cohen 2006) or social capital (Feldman 2001), in the ecosystem. These are tempting concepts to express some fuzzy phenomenon or relationship between people and organizations. Yet, they are such broad terms that they have little power to deconstruct the structure or process toward identifying meaningful implications. Embracing 'risk-taking culture' is indeed important; however, such perceptions do not exist in a vacuum, but will emerge from specific role models, processes, and networks. Mentorship between experienced and nascent entrepreneurs transcends 
the role models, and the connections between those entrepreneurs form the processes and networks.

We believe that our research has deepened understanding of this 'cultural' aspect. Attitudes toward risk-taking can be perpetuated through the ecosystem because entrepreneurs shared their experiences, which were by definition risk-taking. Then, entrepreneurs could comment on others' activities, receive feedback on their own, and change for the better. This mutual process was perceived as the supportive culture. It is harder to change the general culture of people or of a region, but it is easier to introduce these kinds of specific mechanisms through which people interact.

We have to note that these connections for feedback and learning between entrepreneurs were not present in St. Louis several years ago. A director of a support organization used this analogy:

"The typical problem I saw with entrepreneurs five years ago was like this: 'I do this business alone, and I don't know other startups in town. I don't know investors here, and there is only old money from big corporations in St. Louis, so I go to Silicon Valley to find an investor.' Then, if you talked to investors, they would say: 'I don't find any prospective startups in St. Louis, and, in fact, there may not be any startups here, so I go to Silicon Valley to find companies [in which] to invest.' So somehow, they might find each other in Silicon Valley, but not in St. Louis" (Brasunas, interview, December 10, 2012).

These remarks are in sharp contrast to how our interviewees perceived the current supportive and friendly environment among the Arch Grants recipients and between support organizations and mentors. Often, culture is believed not to change quickly, but the specific ways in which people interact could, in fact, change in a matter of five years.
We identified another important factor about the interactions among entrepreneurs and between entrepreneurs and support organizations. The locations of entrepreneurs and support organizations were extremely concentrated, as seen in Figure 5.

This figure depicts a rather boring map with two large concentration spots. The first is in downtown St. Louis, more specifically at 611 Olive Street, $^{5}$ where eight Arch Grants recipients and three support organizations resided. This location was a former department store building, and T-Rex, a space provider for entrepreneurship, occupied five floors. In addition to the eight Arch Grants recipients of 2013, seventytwo other startup firms were operating in the space.

The second is between downtown and Forest Park, more specifically at 4041 Forest Park Avenue, where three biotech firms and one support organization, BioGenerator, were located. The Arch Grants did not require, but encouraged, its recipients to be located in one of these places.

We cannot make a pure causal argument, but we can at least observe that these physical co-locations substantially correlated with the interactions between firms. The Arch Grants required its recipients to relocate to the St. Louis area for at least one year. Three out of twenty recipients have not completely moved to St. Louis yet, and we identify them as having the least interaction with other recipients or support organizations. In contrast, all the most interactive companies were located either at the T-Rex location or at 4041 Forest Park Avenue, shown through larger circles and more central locations in Figures 1, 3, and 4.

We do not mean to argue that proximity sufficiently will create an interacting community of entrepreneurs. As Lichtenstein and Lyons (Lichtenstein and Lyons 2006, 2010) rightly emphasized, entrepreneurs even within the same incubator do not necessarily interact, but catalytic activities to connect them are crucial, often by a person who could

5. The T-Rex facility moved to 911 Washington Avenue, six blocks from 611 Olive Street, in February 2014. 
Figure 5. Map of Arch Grants recipients and support organizations

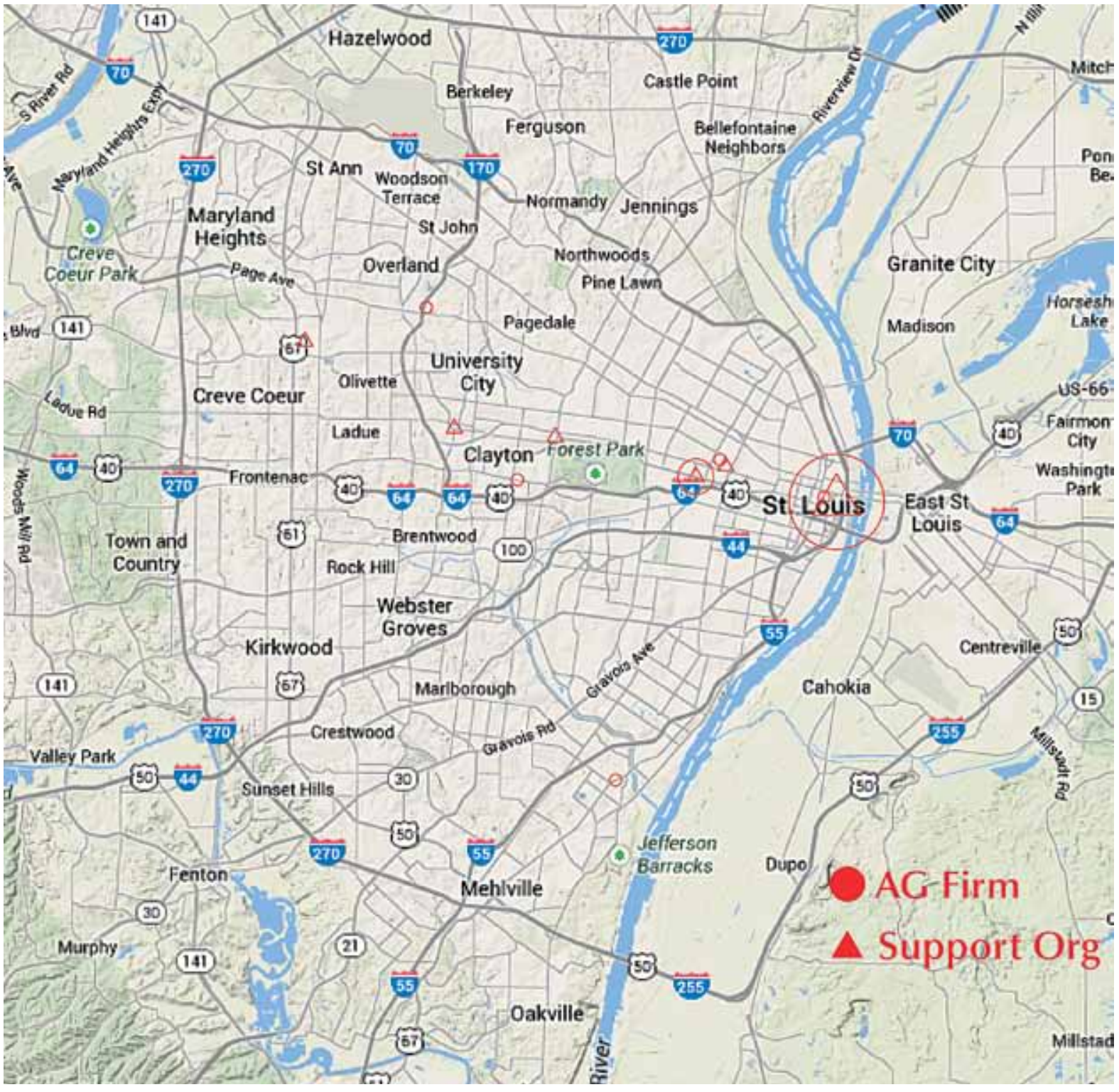

diagnose and assess different stages of development of entrepreneurs. With this case in St. Louis, there seemed to be the right ingredients: those entrepreneurs won the same prize and formed a cohort, and the support organizations also were located at the same facility, provided training, and organized catalytic activities to include the entrepreneurs.
The interviews revealed that support organizations in the region provided somewhat overlapping, yet different, supports based on startups' stages and functions. Analyzing support organizations' responses to the open-ended interview question, "What kind of supports do you provide?," we identified primary types of supports from each organization, 
categorized in Table 3. This table is not intended to be a comprehensive list of support types, but it still captures what each organization considers its primary supports, as well as a good amount of overlap between the organizations.

We classify supports into two large categories: broad and functional. The broad supports are mentoring, finding people, connecting, and financial. The functional supports are more specific, including refining business models, practice pitching to investors and customers, due diligence, and space. Note that the "orthodox" kinds of support for economic development (financial and incubation space) were only two of the many functions these support organizations provided. Moreover, no organization provided money or space alone. The support organizations provided these traditional types of supports in conjunction with other supports.

The previous studies on the entrepreneurship ecosystem discussed little about the content of support services, but rather treated it as a black box. At best, Feldman (Feldman 2001) identified entrepreneurial support services as one element of the ecosystem and observed somewhat different types of supports. Our research contributes to establishing that there are a number of support types, of which our findings identified two handfuls, and that those support types do not fall into the clear-cut categories appearing in business school textbooks, such as finance, accounting, management, marketing, legal, and so on. The categories of supports provided by support organizations and identified by entrepreneurs were much more heterogeneous and subdivided. This finding underscores the important need for further research on this subject.

Perhaps the most heterogeneous support was mentoring, which many support organizations identified as their primary service. We still have only limited knowledge about the exact content of mentoring. It could encompass other functions listed here as subcategories, such as refining the business model, finding the best-fit talent, managing cash flow, or achieving work-life balance. At least, we did find that those mentors worked with nascent entrepreneurs on a purely voluntary basis and did not receive monetary incentives for consultation. The mentors went through similar processes in their past and faced challenges, and they were willing to "give back" to the new generation through mentoring. In that sense, mentor-based support is contextually different from the presence of professional and support services that

\section{Table 3. Types of Primary Supports Provided by Key Support Organizations}

\begin{tabular}{|c|c|c|c|c|c|c|c|c|}
\hline \multirow[b]{2}{*}{ Organizations } & \multicolumn{4}{|c|}{ Broad } & \multicolumn{4}{|c|}{ Functional } \\
\hline & Mentoring & $\begin{array}{l}\text { People } \\
\text { finding }\end{array}$ & $\begin{array}{l}\text { Connect- } \\
\text { ing }\end{array}$ & Financial & $\begin{array}{c}\text { Refine } \\
\text { business } \\
\text { model }\end{array}$ & $\begin{array}{l}\text { Practice } \\
\text { pitching }\end{array}$ & $\begin{array}{c}\text { Due } \\
\text { diligence }\end{array}$ & $\begin{array}{c}\text { Space / } \\
\text { Incuba- } \\
\text { tion }\end{array}$ \\
\hline ITEN & $x$ & $x$ & $x$ & & $x$ & $x$ & & \\
\hline Skandalaris Ctr. & & $x$ & & & $X$ & & & \\
\hline BioGenerator & $x$ & & & $x$ & & & $X$ & $x$ \\
\hline INNOVATE/VMS & $X$ & & $X$ & & & & & \\
\hline Cap. Innovators & $x$ & & $x$ & $x$ & $x$ & $x$ & & $x$ \\
\hline STLVentureWorks & $X$ & & & & & & & $x$ \\
\hline CET & $x$ & & & & $x$ & & & $x$ \\
\hline
\end{tabular}


the cluster theory (Porter 1998) or global city literature (Sassen 2001) identified, and much more locally based and noncommercially oriented.

While further research involving mentors is needed, interviewing only support organizations is insufficient, because these organizations do not necessarily mentor entrepreneurs, but instead introduce mentors to entrepreneurs. Interviewing entrepreneurs may not provide a complete perspective, either, because entrepreneurs may not disclose their most problematic issues. Mentoring is another understudied subject, although some recent research has started to indicate its presence and importance (Motoyama et al. 2013).

One implication about types of supports and support organization is that multiple organizations provided somewhat similar supports, thus overlapping support functions at the regional level, and that such overlap helped entrepreneurs progress through different development stages. Earlier interview quotes revealed that entrepreneurs got financial support from multiple organizations at different times, which helped them to sustain their operations. As such, even within the same function, different support organizations had different niches and training methods. For instance, ITEN provided the Mock Angel Program, in which they trained entrepreneurs to present their business ideas to angel investors. That was contextually different from the pitching practice provided by Capital Innovators, whose primary target was venture capitalists and other institutional investors.

We also observed that each organization had different assets, even within the same training function, and intended to provide complementary supports to companies. At the same time, the emergence of several support organizations in the past few years provided many new opportunities in the region and substantially changed the landscape of entrepreneurship: in addition to the inception of the Arch Grants in 2012, four of the seven support organizations discussed were created since 2011. Some organizations believed that there were redundancies across support systems. Indeed, there was debate about merging some organizations to create efficiencies and simplify things for entrepreneurs.
During our four-month interview period in 2013, two support organizations named new executive directors with strategic intentions to reorganize the organizations' missions, which could suggest constant reorganization of support organizations within a region. This further indicates that identifying and infilling missing types of supports is not sufficient for creating a healthy ecosystem. By definition, a system is a self-regulating mechanism with constant adjustments to its various parts. The entrepreneurship ecosystem is another kind of system, and much effort to analyze missing elements and fulfill them occurs through a mechanism similar to market evolution at the organizational level rather than the top-down method imposed by the public sector. If you inject a new element, it likely will cause adjustments to other elements and the ways different elements interact. What matters is how the ecosystem sustains such change.

Through interviews, we further observed that entrepreneurs tried different support groups without formally joining the group's programs, which clearly shows selective behavior by entrepreneurs and compatibility issues between given support organizations and given entrepreneurs. Support organizations may be tempted to recruit entrepreneurs formally to demonstrate their programs' effectiveness, but they should not be proprietary in this sense and should have open boundaries. A delicate balance is needed, and certain conditions should be avoided, such as "free riding" and getting help without committing due diligence. Constant communication between support organizations seemed to help this aspect. Support organizations were aware of their supported entrepreneurs and had some knowledge about how, and how much, other organizations had helped them. Again, this interconnection between support organizations, the second level of connections, is essential.

It is worth revisiting the role of universities in the entrepreneurship ecosystem. As mentioned, several local universities did play roles in supporting entrepreneurs, but only in specific contexts. First, only firms in the pharmaceutical or biotech sectors had involvement with universities, while firms in 
other sectors, like information technology and manufacturing, did not. There has been much debate about the role of the university as the engine of regional economic development (Fritsch 2002; Kitagawa 2004; Lawton Smith 2007), and those studies argued that the university influence was greater for high-tech or knowledge-intensive industries. Moreover, those studies treated "high-tech" sectors as relatively homogeneous, usually including biotech and pharmaceutical, information technology, and other specialized manufacturing, such as aerospace and precision machinery (see commonly used high-tech definitions (Saxenian 1999; Milken Institute 2011). We find significant heterogeneity within the high-tech sectors in this regard.

Second, as discussed in the analysis section, the common pattern we found was that the founders were students or post-doctoral researchers at universities who applied the technologies of their specialties to commercial settings. In this sense, neither professors nor the technology transfer office was responsible for commercializing university-based technologies. Rather, transfer or commercialization took place through individuals and not through the standard linear model suggested in the literature, such as the Triple Helix model (Etzkowitz 2008; Etzkowitz and Leydesdorff 2000). The creation of patents and licensing were not the observed method by which the university engaged with local entrepreneurship, and scientific knowledge did not trickle down by itself. Compared to faculty and university staff, students and post-doctoral researchers are more mobile, and they themselves transferred and applied their scientific knowledge.

One of the most active support organizations, the Skandalaris Center at Washington University in St. Louis, was by no measure a typical college entrepreneurship center housed within a business school or related to a technology transfer office. In fact, the Skandalaris Center is a special independent unit that reports directly to the university chancellor. Its endowment came from an entrepreneur, who specifically instructed its executive director to be non- academic, and its strategy was way beyond providing standard entrepreneurship courses. The Skandalaris Center's key functions are to motivate and prepare students for early-stage entrepreneurship and to connect students and local startup entrepreneurs by providing student résumés and allowing local entrepreneurs to serve on the judging panel for competitions. Thus, in this sense, the university role, such as business plan writing or accounting, was substantially different from providing a technology transfer office or offering courses through the business school.

Finally, we note that all senior-level staff at support organizations had significant experience in the private sector or as entrepreneurs, and none had backgrounds in traditional economic development agencies. This fact has a significant policy implication. Because they had well-developed networks of their own and knew what kind of experiences each mentor had, these support organization staff could diagnose each entrepreneur's specific entrepreneurial challenge and identify which mentor would be most helpful in that specific context, rather than simply assigning mentors based on generic categories, industrial sectors, and functions of business operation. Thus, knowing potential mentors at only a surface level is not sufficient, and providing a coordinator who would find local mentors, but wasn't part of an existing entrepreneurial network, would unlikely be of help.

\section{POLICY IMPLICATIONS ${ }^{6}$}

Our findings suggest the following strategies may be beneficial in developing a thriving ecosystem of entrepreneurship:

\section{Connect entrepreneurs}

- Entrepreneurs learn from interacting with other entrepreneurs. A strength of the St.

6. This section was jointly written with Jason Wiens, Kauffman Foundation policy director. 


\section{Entrepreneurs learn from interacting with other entrepreneurs.}

Louis startup ecosystem is the extent to which entrepreneurs are connected with others-both peers in similar industries and stages of growth, as well as more experienced entrepreneurs that can serve as mentors.

- Catalytic events, like Startup Weekend or Code Until Dawn, that engage individuals in an entrepreneurial experience are more valuable for building and strengthening ties in a startup ecosystem than are purely networking events like cocktail parties.

\section{Collaborate with other entrepreneurial support organizations}

- Anticipate overlap with other organizations, yet retain a flexible posture. Multiple entrepreneurial support organizations in the St. Louis startup ecosystem offered similar types of support. While our research indicates that overlapping support helped entrepreneurs navigate and progress through different development stages, too much overlapping support should be avoided.

- Communicate and coordinate with other support organizations. Some level of overlapping support can mean constant tension and readjustment between organizations. While there typically is not, and should not be, a single decision-making entity to allocate support functions at the regional level, frequent communication with other organizations should help to identify areas in which support functions overlap and where gaps in service may exist.

- $\quad$ Share information about startups. Overlapping functions mean entrepreneurs may visit several support organizations to find the support needed. However, it should not mean an ecosystem in which entrepreneurs find the least painful advice among different organizations, commit to none, and ignore due diligence, failing to achieve what they promise to accomplish in a given time. To avoid such a situation, support organizations should be aware of the state of each company from perspectives of multiple support organizations.

- Support organizations should cultivate the list of experienced entrepreneurs in the region and selectively connect new and experienced entrepreneurs.

- Clarify navigation of the system for entrepreneurs. Refer entrepreneurs to support organizations that can best meet their needs, resulting in the most efficient use of the region's resources.

- $\quad$ Recruit staff with entrepreneurial experience. In St. Louis, all senior-level staff at support organizations had significant experience in the private sector or as entrepreneurs, which facilitated accurate diagnosis of entrepreneurial problems. Moreover, senior-level staff were able to identify and connect entrepreneurs with specific mentors.

\section{Reinvent investments and incubators}

- If a public venture fund has already been established, distribute many smaller prizes, instead of one large prize, so that a group of entrepreneurs can become a cohort and learn from one another. 
- Note that such cohort connections span industry boundaries, especially for seed and early-stage startups.

- If incubators already exist, reorganize them to connect entrepreneurs and enhance peer-learning. Co-locate and integrate support organizations with incubators.

- Encourage incubators to host activityfocused entrepreneurial events, as opposed to those with a purely "networking" purpose.

\section{CONCLUDING REMARKS}

We were able to pay attention to the interconnections between entrepreneurs and support organizations and reach these findings because we asked questions focused on ground-level observations and entrepreneurs' perspectives: What kind of inputs or supports did you receive for your business? From whom? In contrast, past ecosystem studies used the holistic approach often favored by geographers or economic development scholars: How is the regional entrepreneurship ecosystem structured? What are the regional assets of this area in terms of entrepreneurship? Those holistic questions about the region are fine from a research standpoint, but they are not necessarily compatible with how individual entrepreneurs behave in their daily operations and interactions. We believe that our approach, asking about past experiences and concrete examples from the entrepreneurs' viewpoints, helped to identify more tangible connections within the ecosystem.
The Arch Grants employed a rather unusual approach by distributing small prizes widely-as many as twenty. This was a sharp contrast to most other traditional business plan competitions established by the public sector, in which the first prize was a large sum, as much as $\$ 1$ million, but awarded to no more than a few winners. Additionally, the Arch Grants streamlined carefully to integrate with local entrepreneurship assets, such as encouraging its recipients to operate in specific locations, which further enhanced their interactions, and connecting them to local key support organizations, such as ITEN, BioGenerator, and others.

It is hard to tell if this Arch Grants model will sustain, or if the supported companies will successfully grow. As of December 2013, half a year after the selection, most Arch Grants recipients seemed to be thriving, with 70 percent of them starting to generate revenue. It is even harder to tell how the startup ecosystem will evolve and integrate with the broader St. Louis entrepreneurship ecosystem over the coming yearsonly time will tell. This is the dilemma that social science researchers with no pure experimental design opportunity have to face. However, we hope that some of the key findings and the proposed framework from this research can provide implications for further investigation of the entrepreneurial ecosystem and research methods.

\section{Acknowledgement}

The authors thank Jim Brasunas, Ken Harrington, Andrew Knight, Jason Wiens, Nick Seguin, and Dane Stangler for valuable comments, as well as Michelle St. Claire for a variety of assistance. All the interviewees (entrepreneurs and leaders of support organizations) were generous to give us their time and share their insights.

\section{Holistic questions about the region are fine from a research standpoint, but they are not necessarily compatible with how individual entrepreneurs behave in their daily operations and interactions.}




\section{REFERENCES}

Acs, Z.J., and C. Armington. 2006. Entrepreneurship, geography, and American economic growth. Cambridge: Cambridge University Press.

Amezcua, A.S. 2010. Boon or Boondoggle?: Business Incubation as Entrepreneurship Policy. In Doctoral Dissertation in Public Administration. Syracuse, NY: Syracuse University.

Arch Grants. 2014a. Frequently Asked Questions.

Arch Grants. 2014b. Personal communications of the authors.

Castells, M. 1989. Informational City: Information Technology, Economic Restructuring, and the UrbanRegional Process. Oxford: Blackwell.

Chapman, T. 2011. Building an entrepreneurial ecosystem. Omaha, NE.

Cohen, B. 2006. Sustainable Valley entrepreneurial ecosystem. Business Strategy and the Environment 15:1-14.

Cohn, C. 2013. St. Louis: A model for aspiring tech hubs. In Forbes.

Cooke, P. 1998. Introduction: Origins of the Concept. In Regional Innovation Systems: the Role of Governances in a Globalized World, ed. H.-J. Braczyk, P. Cooke, and M. Heidenreich, 2-25. London: UCL Press.

Cooke, P., and K. Morgan. 1998. The Associational Economy: Firms, Regions, and Innovation. Oxford: Oxford University Press.

De la Merced, M.J. 2008. InBev to buy Anheuser-Busch for $\$ 52$ billion. In New York Times. New York.

Etzkowitz, H. 2008. The triple helix: University-industry-government innovation in action. New York: Routledge.

Etzkowitz, H., and J. Dzisah. 2008. Unity and diversity in high-tech growth and renewal: Learning from Boston and Silicon Valley. European Planning Studies 16:1009-1024.

Etzkowitz, H., and L. Leydesdorff. 2000. The dynamics of innovation: from National Systems and "Mode 2" to a Triple Helix of university-industry-government relations. Research Policy 29:109-123.

Feld, B. 2012. Startup communities: Building an entrepreneurial ecosystem in your city. Hoboken, NJ: John Wiley \& Sons.

Feldman, M. 2001. The entrepreneurial event revisited: Firm formation in a regional context. Industrial and Corporate Change 10:861-891.

Feldman, M.P. 2003. Entrepreneurship and American Research Universities: Evolution in Technology Transfer. In The Emergence of Entrepreneurship Policy; Governance, Start-ups, and Growth in the U.S. Knowledge Economy, ed. D.M. Hart, 92-112. Cambridge: Cambridge University Press.

Fritsch, M. 2002. Measuring the quality of regional innovation systems: A knowledge production function approach. International Regional Science Review 25:86-101. 
Haltiwanger, J. 2012. Job creation and firm dynamics in the U.S. Innovation Policy and the Economy 12:17-38.

Haltiwanger, J., R.S. Jarmin, and J. Miranda. 2013. Who creates jobs? Small vs. large vs. young. Review of Economics and Statistics 95:347-361.

Hwang, V.W., and G. Horowitt. 2012. The Rainforest: The Secret to Building the Next Silicon Valley. CreateSpace Independent Publishing Platform.

Isenberg, D. 2013. Worthless, Impossible and Stupid: How Contrarian Entrepreneurs Create and Capture Extraordinary Value. Boston: Harvard Business Review Press.

Kenney, M. 2000. Understanding Silicon Valley: The Anatomy of an Entrepreneurial Region. Palo Alto: Stanford University Press.

Kitagawa, F. 2004. Universities and regional advantage: Higher education and innovation policies in English regions. European Planning Studies 12:835-852.

Knowlton, B. 1996. Boeing to buy McDonnell Douglas. In New York Times. New York.

Konczal, J. 2013. The most entrepreneurial metropolitan area? In Kauffman Foundation Research Papers. Kansas City, MO: Ewing Marion Kauffman Foundation.

Lawton Smith, H. 2007. Universities, innovation, and territorial development: A review of the evidence. Environment and Planning C: Government and Policy 25:98-114.

Lecuyer, C. 2006. Making Silicon Valley: Innovation and the growth of high tech, 1930-1970. Cambridge, MA: MIT Press.

Lerner, J. 2009. Boulevard of broken dreams: Why public efforts to boost entrepreneurship and venture capital have failed and what to do about it. Princeton: Princeton University Press.

Lichtenstein, G.A., and T.S. Lyons. 2006. Managing the community's pipeline of entrepreneurs and enterprises: A new way of thinking about business assets. Economic Development Quarterly 20:377-386.

- 2010. Investing in entrepreneurs: A strategic approach for strengthening your regional and community economy. Santa Barbara, CA: Praeger.

Lundvall, B.-A. 1992. National systems of innovation: towards a theory of innovation and interactive learning. London, New York: St. Martin's Press.

Malecki, E.J. 1994. Entrepreneurship in regional and local development. International Regional Science Review 16:119-153.

Marshall, A. 1898. Principles of Economics. London: Macmillan and Company.

Milken Institute. 2011. State technology and science index 2010: Enduring lessons for the intangible economy, ed. R.C. DeVol, K. Klowden, and B. Yeo. Santa Monica, CA: Milken Institute.

Motoyama, Y. 2008. What was New About the Cluster Theory?: What Could It Answer and What Could it Not Answer? Economic Development Quarterly 22:353-363. 
Motoyama, Y., and B. Danley. 2012. The ascent of America's high-growth companies: An analysis of the geography of entrepreneurship. In Kauffman Research Paper Series. Kansas City, MO: Kauffman Foundation.

Motoyama, Y., B. Danley, J. Bell-Masterson, K. Maxwell, and A. Morelix. 2013. Leveraging regional assets: Insights from high-growth companies in Kansas City. In Kauffman Foundation Research Paper. Kansas City, MO: Kauffman Foundation.

Moules, J. 2014. The secret life of start-ups in 'KC'. In Financial Times, 8. London.

MTC. 2013. Sparking innovations: 2013 annual report. St. Louis, MO: Missouri Technology Corporation.

Neck, H.M., G.D. Meyer, B. Cohen, and A. Corbett. 2004. An entrepreneurial system view of new venture creation. Journal of Small Business Management 42:190-208.

Porter, M.E. 1994. The Role of Location in Competition. Journal of the Economics of Business 1:35-39. 1998. The Adam Smith Address: Location, Clusters, and the New Microeconomics of Competition. Business Economics 33:7-14.

—. 1998. Clusters and the New Economics of Competition. Harvard Business Review 76:77-90.

- 2000. Location, Competition, and Economic Development: Local Clusters in a Global Economy. Economic Development Quarterly 14:15-34.

Reilly, C. 2014. Boom: St. Louis' startup business scene is on the fast track. In ALIVE, 69-80. St. Louis: ALIVE Magazine.

Sassen, S. 2001. The Global City: New York, Tokyo, London. Princeton: Princeton University Press.

Saxenian, A. 1994. Regional advantage: culture and competition in Silicon Valley and Route 128. Cambridge, Mass.: Harvard University Press.

1999. Silicon Valley's new immigrant entrepreneurs. San Francisco: Public Policy Institute of California.

Schumpeter, J.A. 1912. Theorie der wirtschaftlichen entwicklung (Theory of Economic Development). Leipzig: Duncker \& Humblot.

Van de Ven, A. 1993. The development of an infrastructure for entrepreneurship. Journal of Business Venturing 8:211-230. 


\section{APPENDIX 1: LIST OF INTERVIEWEES}

\begin{tabular}{|c|c|c|}
\hline Organization & Interviewee Name(s) & Date \\
\hline ITEN & Jim Brasunas & $8 / 1 / 2013$ \\
\hline 1 Million Cups & Francis Chmelir & $8 / 1 / 2013$ \\
\hline Skandalaris Center & Ken Harrington & $8 / 6 / 2013$ \\
\hline BioGenerator & Eric Gulve & $10 / 1 / 2013$ \\
\hline INNOVATENMS & Phyllis Ellison & $10 / 29 / 2013$ \\
\hline Capital Innovators & Matt Menietti & $11 / 15 / 2013$ \\
\hline STLVenture Works & Travis Sheridan & $12 / 9 / 2013$ \\
\hline Arch Grants & Ginger Imster & $2 / 13 / 2014$ \\
\hline Appcropolis & Raul Sanchez & $8 / 2 / 2013$ \\
\hline Juristat & Drew Winship & $8 / 5 / 2013$ \\
\hline TrakBill & Steven Marciniak & $8 / 20 / 2013$ \\
\hline Immunophotonics & Lu Alleruzzo & $8 / 22 / 2013$ \\
\hline Genetix Fusion & Mohit Patel & $8 / 29 / 2013$ \\
\hline MMBiosensing & Amos Danielli & $9 / 6 / 2013$ \\
\hline Sparo Labs & A. Brimer, A. Cohen, W. Dahl & $9 / 19 / 2013$ \\
\hline Eterno Gen & Ron Bassuner & $9 / 24 / 2013$ \\
\hline Triflare & Andrea Robertson & $9 / 26 / 2013$ \\
\hline Rovertown & Jeffry Harrison & $11 / 18 / 2013$ \\
\hline U.S. Drilling Products & Chuck Lee & $12 / 2 / 2013$ \\
\hline Adarza Biosystems & Rand Henke & $12 / 3 / 2013$ \\
\hline Code Red & Michael Palmer & $12 / 3 / 2013$ \\
\hline Lipospectrum & Millind Sant & $12 / 5 / 2013$ \\
\hline Knowlnk & Scott Leiendecker & $12 / 13 / 2013$ \\
\hline AdFreeq & Peter Meng & $1 / 16 / 2014$ \\
\hline
\end{tabular}

\section{APPENDIX 2: PERFORMANCE OF 2013 ARCH GRANTS RECIPIENTS}

\begin{tabular}{|l|c|c|c|c|}
\hline 2013 Cohort & $10 / 1 / 2013$ & $1 / 1 / 2014$ & $4 / 1 / 2014$ & $7 / 1 / 2014$ \\
\hline Jobs & 67 & 73 & 99 & 104 \\
\hline Revenue & $\$ 197,374$ & $\$ 957,265$ & $\$ 1,887,545$ & $\$ 2,862,700$ \\
\hline Capital & $\$ 6,695,433$ & $\$ 7,443,433$ & $\$ 14,363,433$ & $\$ 17,907,251$ \\
\hline
\end{tabular}

Source: Arch Grants (2014b). 
(

(1)

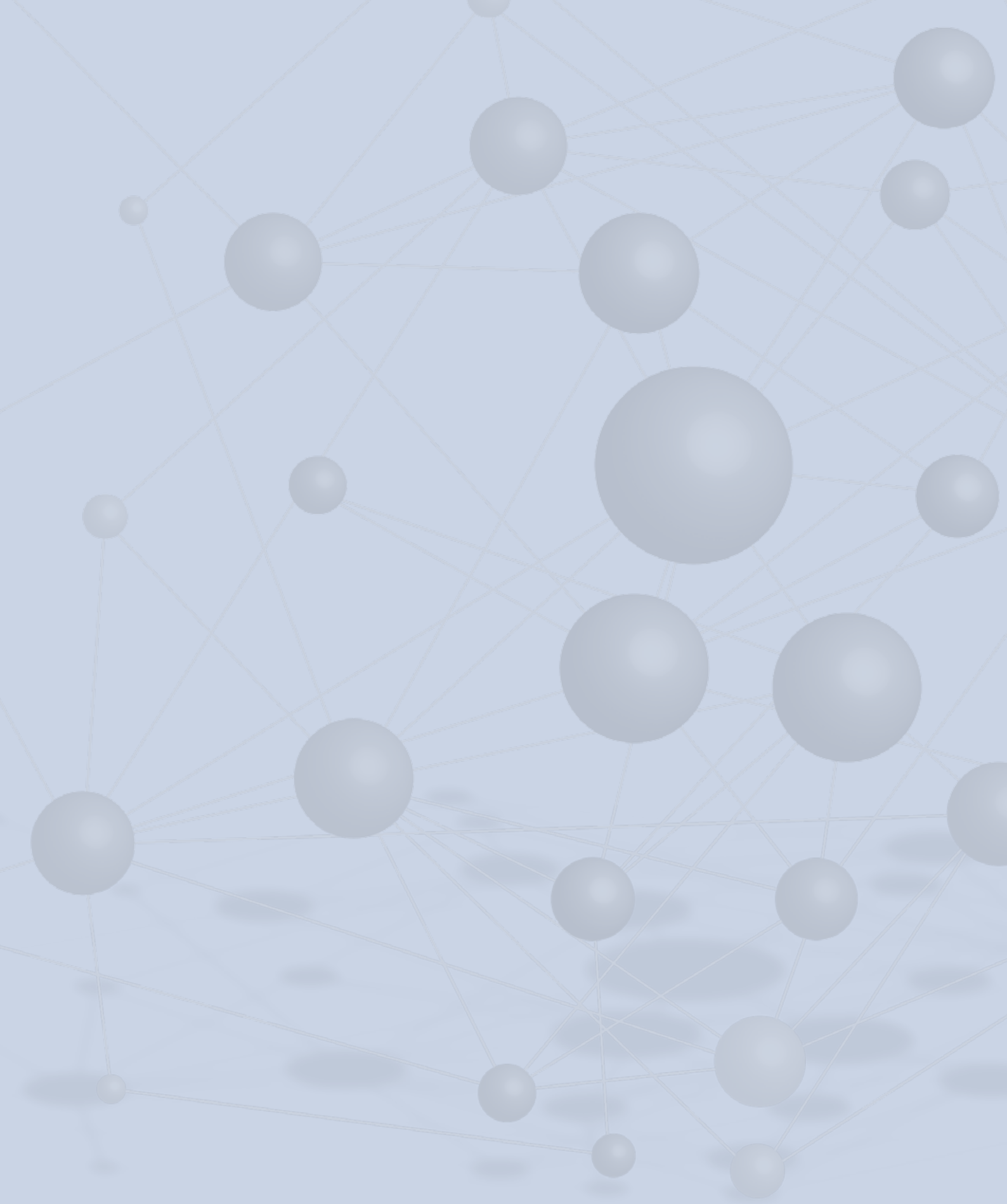


Ewing Marion

\section{KAUFFMAN \\ Foundation}

4801 ROCKHILL ROAD

KANSAS CITY, MISSOURI 64110

816-932-1000

www.kauffman.org 